\title{
ACHANDO REPOUSO PARA A BÚSSOLA DO CORAÇÃO: O CONCEITO HEBRAICO DE TEMPO EM KIERKEGAARD
}

\section{FINDING REST FOR THE HEART COMPASS: THE HEBREW CONCEPT OF TIME IN KIERKEGAARD}

\author{
André Oswaldo V. Ribeiro*
}

\begin{abstract}
Resumo: Nos estudos sobre Kierkegaard e a tradição judaica, é comum a discussão da análise kierkegaardiana da aqedah de Isaac. No entanto, um aspecto decisivo da antropologia de Kierkegaard é o problema da experiência do tempo. Neste artigo, discutiremos dois modos antagônicos de vivenciar o tempo: o desespero de um tempo corrosivo versus a confiança proveniente de um tempo dentro da eternidade. Analisaremos a relação entre a antropologia de Kierkegaard e a noção hebraica de tempo que emerge do relato cosmogônico de Gn 2 mediante o exame de três categorias existenciais kierkegaardianas: o instante, a repetição e a contemporaneidade consigo mesmo. Partindo da torah e de uma anotação de Kierkegaard sobre o tempo judaico escrita em 1837, discutiremos os mistérios e os dramas da experiência do tempo no seio de uma antropologia da redenção do homem e do tempo.
\end{abstract}

Palavras-chave: Consciência. Tempo. Eternidade. Dissipação. Redenção.

\begin{abstract}
In studies of Kierkegaard and Jewish tradition, discussion of the Kierkegaardian analysis of Isaac's aqedah is common. However, a decisive aspect of Kierkegaard's anthropology is the problem of the experience of time. In this article, we will discuss two antagonistic ways of experiencing time: the despair of corrosive time versus the confidence that comes from a time within eternity. We will analyze the relationship between Kierkegaard's anthropology and the Hebrew notion of time that emerges from the cosmogonic account of Genesis 2 by examining three Kierkegaardian existential categories: the instant, repetition and contemporaneity with oneself. Starting from the torah and a note by Kierkegaard on Jewish time written in 1837, we will discuss the mysteries and dramas of the experience of time within an anthropology of the redemption of man and time.
\end{abstract}

Keywords: Consciousness. Time. Eternity. Dissipation. Redemption.

Como o homem experimenta o tempo? De que modo o vivenciar? Como uma fornalha devoradora dos instantes, ou como uma realidade plena de sentido eterno? A antropologia do

\footnotetext{
${ }^{*}$ Mestre em Estudos Judaicos pela FFLCH/USP, Doutor em Filosofia pela Escola de Filosofia, Letras e Ciências Humanas da UNIFESP.

Email: 〈andreoswaldo2014@gmail.com>.
} 
tempo está no coração da fé judaica e no âmago do pensamento existencial de Kierkegaard. Neste artigo discutiremos dois modos de vivenciar o tempo: uma experiência desesperada do tempo - o tempo como agente corrosivo, e uma experiência sagrada do tempo - o tempo como receptáculo da redenção. Discutiremos a presença do conceito hebraico de tempo em três categorias existenciais: o instante, a repetição e a contemporaneidade consigo mesmo, três noções importantes na antropologia de Kierkegaard.

Qual é o conceito de tempo presente na torah? O livro de Bereshit apresenta a história humana como uma história de alinhamento e desalinhamento da bússola do coração humano às diretrizes divinas presentes na sua palavra-ato (dabar). O coração, no sentido hebreu e arcaico, não é pensado como órgão emocional (função atribuída à nefeš), mas como órgão dos discernimentos e das decisões, como órgão das cesuras intelectuais e morais ${ }^{1}$. Segundo Wolff,

raramente o termo le $\underline{b}$ significa sentimento (Gemut) [na bíblia hebraica]; pelo contrário, com muito mais frequência indica clara e propriamente o órgão do conhecimento, e finalmente a vontade unida a ele, os seus planos, resoluções e intenções (...) Sem dúvida abrange as áreas do corporal, do emocional, do intelectual e das funções da vontade, mas deve-se reter com a mesma clareza que a bíblia vê no coração do homem antes de tudo o centro do homem que vive de modo cônscio. O proprium de ampla repercussão é que o coração é chamado a ter juízo, principalmente para a percepção da palavra de Deus. (WOLFF, 1975, p.81)

A tarefa do coração como órgão da consciência é uma tarefa perceptivo-deliberativa. Essa tarefa existencial do hebreu está na contida na interjeição que sumariza a fé judaica: šema ! A raiz šm ' contém duas significações coligadas: ouvir e responder (guardando, no sentido moral, o que foi ouvido). Esta é a tarefa precípua a ser realizada dentro do tempo: percepcionar com os ouvidos do coração a palavra-ativa do Eterno. A torah, por sua vez, apresenta a história humana como uma história marcada pelos dramas "eletromagnéticos" do coração em face do magnetismo celestial. A dificuldade da bússola do coração alinhar-se ao pólo magnético do Deus de Abraão.

Tal dificuldade atravessa a história como drama permanente que alcança os tempos modernos de um modo sui generis:

Sabemos o que fazer com o espaço, mas não sabemos o que fazer com o tempo. (...) Sofremos de um temor pelo tempo, e ficamos consternados quando compelidos a olhar em sua face. Segundo Berdiaev, "o tempo é uma doença mortal, destilando uma nostalgia fatal. A passagem do tempo golpeia o coração do homem com desespero". O tempo para nós é um monstro traiçoeiro

\footnotetext{
${ }^{1}$ Tanto discernere como decidere contém etimologicamente o sentido de corte e de separação. 
com uma fornalha na boca incinerando cada momento de nossas vidas. Esquivando-se de enfrentar o tempo, buscamos abrigo nas coisas do espaço. As intenções que não podemos realizar nós as depositamos no espaço; as posses se tornam símbolos de nossas repressões, jubileus de frustrações. Mas as coisas do espaço não são à prova de fogo. (...) Não devemos esquecer que não é uma coisa que empresta significação a um momento; é o momento que empresta significação às coisas (HESCHEL, 2014, p.12-13).

Heschel descreve a consciência moderna do tempo. A bicicleta sujeita a ferrugem. O relógio biológico em contagem regressiva. Não obstante as alegadas luzes da aufklärung, a visão moderna é de um tempo opaco e nublado. O tempo reduzido a corrosão e dissipação se tornou um drama epocal. No entanto, mutatis mutandis, desde os primórdios a dificuldade com o tempo está posta e pressuposta. Sendo o Deus de Israel apresentado pela bíblia hebraica como metaonisciente, como absolutamente soberano sobre tudo, é natural que, no nascedouro, no relato cosmogônico, já esteja posto ou pressuposto a terapêutica contra todos os grandes males da existência. A dificuldade em lidar com o tempo, a bússola desnorteada do coração, tem a sua terapêutica posta desde a primeira semana da criação.

Na visão judaica, o reajuste da agulha do coração, da seta do tempo, do sentido da vida acontece mediante a prática do šema . O homem mais sábio da história se tornou sábio de que modo? Quando teve a oportunidade, Salomão pediu a Deus "um coração que escuta" (le $\underline{b}$ šomea) (1 Rs 3,9). A raiz šm ' designa o ato de ouvir-e-responder, um ato de efetiva consideração e contemplação. Na torah, é pela contemplação ativa dos atos da criação que a angústia do tempo é tratada. O mistério do tempo é o mistério da criação. O primeiro ato de santificação de Deus é a santificação do tempo:

Assim foram acabados os céus e a terra e tudo o que neles há. E, havendo Deus terminado no sétimo dia a obra que tinha realizado, repousou nesse dia de toda a obra que tinha realizado. E Deus abençoou o sétimo dia e o santificou; porque nele Deus repousou de toda a obra que tinha realizado e criado ( $\mathrm{Gn}$ 2,1-3, grifo nosso)

Deus cria pela palavra. Após o ato da criação (ma 'ase berešit) dos céus, da terra e do que neles há em seis dias, no sétimo dia Deus realiza mais três ações solenes, ações distintas das obras anteriores, ações designadas por três raízes: šbt, brk, e qď́ - repousar, abençoar e santificar, respectivamente. Os três verbos são organizados assim: Deus abençoa e santifica o sétimo dia porque nele repousou das obras que havia realizado. Nesse início de Genesis 2 há 
uma ênfase na expressão $m^{e} l a^{\prime} k t o w$ 'ašer 'asah, "obra que havia realizado", repetida três vezes. Na terceira ocorrência (v.3) há uma inserção: melaktow 'ašer bara' la'asot, "obra que tinha criado e realizado". O repouso é o que se sucede às obras. O repouso divino é colocado como razão da benção e da separação deste dia em relação aos outros seis. O repouso divino contém bênção e distinção em si mesmo. No repouso de Deus está a chave da experiência do tempo. No fim da criação está o fim da criação - no desfecho está a sua finalidade. Podemos dizer que a ontologia fundamental do homem está no sétimo dia da criação. A terapêutica hebraica para a percepção do tempo como fornalha monstruosa é uma tríade cosmogônica redentora, nessa

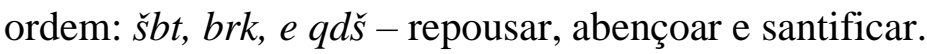

É na apropriação dessa tríade redentora que o homem redime o tempo. A base da tríade é o repouso (šbt). O repouso de Deus sendo apropriado pelo homem e se tornando repouso divino no repouso humano - a eternidade dentro do tempo. O šbt é o átomo do tempo, o referencial da vivência sagrada do tempo. Além do relato da criação, o texto sobre as festas anuais é outra evidência disso:

O Senhor disse a Moisés: Fale aos filhos de Israel e diga-lhes: As festas fixas [mo'ade, períodos] do Senhor, que vocês proclamarão, serão santas convocações; são estes os meus tempos determinados [mo 'aday]. (Lv 23,1-2)

Comumente traduzido como festa, o termo mo 'ed significa "tempo determinado, lugar determinado, tempo de encontro" (BDB, 2006). Esse texto da torah (Lv 23) prescreve os sete principais tempos pré-estabelecidos no calendário, sete momentos de encontro anuais do Deus de Israel com o seu povo:

\begin{tabular}{|c|c|}
\hline pessaḥ & páscoa \\
\hline mașot & ázimos \\
\hline rešit & primícia \\
\hline šavuot & Semanas \\
\hline yom teruah & Dia do toque \\
\hline yom kipur & Dia da expiação \\
\hline sukkot & tabernáculos \\
\hline
\end{tabular}

De modo sintomático, o capítulo da torah sobre os sete tempos anuais pré-determinados por Deus tem como cabeçalho o mandamento do repouso no sétimo dia. "Seis dias trabalharão, mas o sétimo dia é šabat de repouso, santa convocação" (Lv 23,3). Há uma reiteração textual: 
o sétimo dia é šabat šabaton, miqra qodeš, "repouso sobre repouso, sagrada proclamação". Esta prescrição, posta como caput do capítulo, coloca o šbt semanal como átomo dos sete tempos anuais do calendário bíblico. O termo mo ed vem da raiz y'd que significa mira, alvo, destinação. O repouso de Deus é o ponto de partida e o ponto de destino dos tempos determinados de Deus. O criador do tempo porta no seu próprio exemplo o paradigma redentor do tempo: seu repouso gera benção e santidade que se distendem sobre o tempo. A tríade cosmogônica redentora ecoa vida no tempo cronológico, transmutando o instante dissipativo em instante eterno.

Kierkegaard e a vivência judaica do tempo como instante (øieblik) e como contemporaneidade consigo mesmo (Samtidighed sig selv)

O mês judaico começa com a lua nova, mas o šabat não depende do mês nem da lua. Sua data não é determinada por nenhum evento na natureza, mas pelo ato da criação. (...) O sábado não tem o propósito de recuperar as forças perdidas (concepção aristotélica de repouso), ou de melhorar a eficiência no trabalho. O sábado não existe em consideração aos dias da semana, mas os dias da semana existem em consideração ao sábado. (...) No sábado somos chamados a partilhar do que é eterno no tempo, para fugir dos resultados da criação para os mistérios da criação (HESCHEL, 2014, p18-19.24, grifo nosso)

Segundo a torah, o šbt é um sinal de aliança entre Deus e seu povo (Ex 31,16). Nos termos da literatura profética, o šbt foi dado ao homem para o seu deleite (Is 58,13). Aliança e deleite, aspectos da presença do eterno do tempo, aspectos contidos na noção de šbt. O šbt é uma noção decisiva na antropologia de Kierkegaard. Em uma de suas inúmeras anotações, datada do início de sua obra (30/06/1837), Kierkegaard divisa explicitamente a singularidade da concepção judaica do tempo:

A Idade Média como romantismo percebia apenas um lado da eternidade - o desaparecimento do tempo (inúmeros poemas medievais servem de exemplo); mas não percebia, como os judeus, o outro lado, a interioridade do tempo na eternidade. Idade Média, leia-se: mil anos é como um dia; mas não um dia é como mil anos, porque com esforço se obteve um instante abençoado; mas não uma benção eterna. A propósito, é mais do que um simples paralelismo linguístico - para Deus mil anos é como um dia e um dia como mil anos - é muito mais do que uma legítima declaração especulativa, pois ela não suprassume nem nulifica o conceito de tempo; antes o preenche 
[fuldstondiggjør, torna pleno] (KIERKEGAARD, DD:16/1837, SKS 17,224, grifo nosso) $)^{2}$.

O momento biográfico dessa anotação dentro da trajetória de Kierkegaard como escritor é digno de nota. Kierkegaard escreveu essa anotação aos 24 anos, em 1837. Ela precede a sua primeira obra publicada (Papeis de um ainda vivente), de 1838. A percepção da singularidade da compreensão judaica do tempo, posta logo no início de sua trajetória intelectual, divisa um insight que, ousamos dizer, iria se desdobrar pelos próximos 18 anos seguintes, isto é, ao longo de toda a sua obra como pensador da existência em geral e pensador da existência cristã em particular. A defesa dessa tese foge ao escopo desse artigo. No entanto, a discussão a seguir aponta elementos que a corroboram ${ }^{3}$.

O primeiro aspecto da anotação de Kierkegaard sobre os judeus é o contraste da visão judaica do tempo em relação ao sentimento romântico do tempo, o tempo como dissipação ou fornalha devoradora. Kierkegaard expressa seu contraste utilizando uma frase clássica da literatura bíblica, extraída do livro dos salmos:

eleph šanim beneka $k^{e}$ yom ki ya'abor weašmurah balayelah.

mil anos à sua vista são como o dia de ontem que passou ['abar], como uma das vigílias da noite. (Salmo 90,4)

O salmo 90 é um poema meditativo sobre a brevidade do tempo humano em face da eternidade de Deus. Um poema que começa reconhecendo a indignidade humana para chegar a uma súplica em busca da graça que concede alegria e discernimento ("ensina-me a numerar os meus dias de modo a alcançar um coração sábio”, S1 90,12). O conteúdo existencial do salmo

\footnotetext{
${ }^{2}$ Middelalderen som romantis[k] opfattede kun den ene Side af Evigheden - Tids Forsvinden (cfr. Digte fra Middel: mange Exempler - Syvsovere etc.); men ikke som Jфderne den anden Tids Inderligheden i Evigheden. Midd: siger vel: 1000 Aar er som een Dag; men ikke een Dag er som 1000 Aar, fordi den som strabende vel havde et Saligheds Øieblik; men ikke en Evigheds Salighed. Forфvrigt er det mere end den simple Paralellisme der ligger i de Ord: 1000 Aar er for Gud som 1 Dag, og 1 Dag som 1000 Aar det er meget mere et agte speculativt Udsagn, idet det ikke ophover og tili(nte)tgjфr Tidsbegrebet; men fuldstondiggjфr det.

${ }^{3}$ A discussão sobre a raiz judaica da revelação cristã explica uma parte dessa questão. No entanto, trata-se de um aspecto abrangente que também foge ao escopo desse artigo, haja vista a singularidade de Kierkegaard em relação a outros pensadores protestantes, como, por exemplo, Luthero. Mesmo que não tenha se afastado de iure de Israel, de facto Luthero adotou uma posição anti-Israel em uma de suas últimas obras (Os judeus e suas mentiras, publicado em 1543). Kierkegaard, por sua vez, não obstante a sua recepção do legado doutrinário luterano, manifesta na sua obra traços nítidos da cultura judaica no seio da qual a revelação cristã emerge. Além da questão do tempo, discutida nesse artigo, outro aspecto é a noção de ação, a qual discutimos em outro artigo, ainda no prelo.
} 
se reflete na forma: o salmista, tal como a vida humana, passa pelo reconhecimento da merecedora fúria divina (S1 90, 7-11) rumo a este desfecho - uma posição de súplica por misericórdia: "seja a graça [noam, deleite] do Senhor nosso Deus sobre nós” (S1 90,17).

É deste poema sobre Deus e os homens em face do tempo que Kierkegaard extraí a clássica frase "mil anos para Deus é como um dia". No entanto, Kierkegaard cita essa frase na sua releitura cristã presente na segunda carta de Pedro, que a amplia utilizando o paralelismo típico da didática hebraica: "para o Senhor um dia é como mil anos, e mil anos como um dia" (2 Pd 3,8). Kierkegaard, por sua vez, confere um sentido singular a essas duas frases, utilizandoas como emblemas do contraste entre a visão judaica do tempo e a visão romântica do tempo. Segundo Kierkegaard, a visão romântica do tempo se expressa na primeira parte (mil anos é como um dia). Kierkegaard captura o sentido figurado redutor para designar um sentido reducionista do tempo - a efemeridade de um milênio. Por outro lado, a segunda parte da expressão (um dia é como mil anos) possui, no argumento de Kierkegaard, um sentido infinitamente distinto. Kierkegaard captura o sentido figurado ampliador para designar um sentido robusto de tempo - a perenidade de um ciclo diário. Considerando a frase no contexto do salmo 90, onde se afirma que mil anos é como a fração de um dia (uma parte da vigília, uma fração da madrugada), podemos dizer, seguindo o raciocínio de Kierkegaard, que uma fração do dia é como mil anos; um instante é como um milênio. Esta é, segundo Kierkegaard, a singularidade da visão judaica de tempo que o pensamento romântico é incapaz de compreender: a eternidade dentro do tempo, o chamado "instante" (фieblik).

Desenvolvendo a visão judaica do tempo na obra Conceito de Angústia, de 1844, Kierkegaard afirma que o instante "não é o átomo do tempo, mas sim o átomo da eternidade [Evighedens Atom]”, “o primeiro reflexo da eternidade no tempo", algo que "os gregos não conseguem entender” (KIERKEGAARD, SKS 4,391). Por que não conseguem compreender? Essencialmente, porque se trata de um conceito judaico, de uma cosmovisão estranha ao seu pensamento. Segundo Kierkegaard,

O instante é aquela ambiguidade em que o tempo e a eternidade se tocam, e com isso se estabelece o conceito de temporalidade, onde o tempo corta constantemente a eternidade e a eternidade permeia [gjennemtranger, impregna] constantemente o tempo ${ }^{4}$ (KIERKGAARD, SKS 4,392).

\footnotetext{
${ }^{4}$ Øieblikket er hiint Tvetydige, hvori Tiden og Evigheden berфre hinanden, og hermed er Begrebet Timelighed sat, hvor Tiden bestandig afskarer Evigheden og Evigheden bestandig gjennemtranger Tiden.
} 
Como já discutimos, esta noção de instante ou momento cujo conteúdo qualitativo suprarracional é constituído pela intersecção entre tempo humano e tempo divino é o conceito judaico de šbt. Kierkegaard conclui a anotação de 1837 afirmando que o provérbio “[para Deus] mil anos é como um dia e um dia é como mil anos" não é "uma declaração especulativa, pois ela não suprassume nem nulifica o conceito de tempo, mas antes o plenifica”. Kierkegaard demarca campos distintos: de um lado, o pensamento especulativo hegeliano de sua época (Kierkegaard utiliza o termo dinamarquês ophave, equivalente do termo alemão aufheben, suprassumir); de outro lado, o conceito judaico de tempo, que preenche o tempo com conteúdo eterno, com a tríade redentora (repouso, benção e santificação) que divisa a Tids Inderligheden i Evigheden, a "interioridade [ou interiorização] do tempo na eternidade".

Destarte, enquanto na obra Conceito de Angústia, de 1844, a noção judaica de tempo se faz presente através da noção de instante, na obra A repetição, de 1843 , encontramos outra noção decisiva da antropologia de Kierkegaard que é derivada do conceito judaico de tempo: a noção de contemporaneidade consigo mesmo (Samtidighed sig selv). Embora essa expressão seja de uma obra de 1848 (Christelige Taler, "Discursos do evangelho"), a discussão kierkegaardiana sobre Jó descreve o que posteriormente Kierkegaard chamaria de contemporaneidade consigo mesmo.

Já no título da obra e nome do pseudônimo (Constantin Constantius) Kierkegaard tematiza a vivência dramática do tempo em busca da constância. Constâncio discute o caso de um jovem melancólico que se aproxima da cura de seu estado (a fé), mas não a alcança. Kierkegaard equivale a melancolia ao desespero (KIERKEGAARD, SKS 7,230), o qual, segundo Kierkegaard, é uma doença da consciência e oposto da fé (cf. IDEM, SKS 11). Ecoando a anotação de 1837, Kierkegaard discute o caso de um rapaz que rejeita uma visão especulativa do tempo, aproximando-se de um personagem hebreu, que vê o tempo de um modo plenificado:

O problema [Det Problem] com o qual o jovem se defronta é nada mais nada menos do que a repetição. Ele não busca clarificação nem na filosofia grega nem na nova filosofia, e está certo, pois os gregos fazem o movimento inverso, apenas recordando, (...) e a nova filosofia (...) se restringe à imanência. (...) Para mim também a repetição é demasiado transcendente. Eu posso rodear a mim mesmo, mas eu não sou capaz de ir acima de mim mesmo, esse ponto de Arquimedes eu não consigo achar. O meu amigo felizmente não procura clarificação [Oplysning] em algum filósofo mundialmente famoso ou em algum professor publicus ordinarius; ele se volta para um pensador em sua vida particular: (...) Ele volta-se para Jó, que não ocupa uma cátedra nem se põe a garantir a verdade de suas proposições com a segurança de sua gesticulação, mas sentado sobre a cinza raspa suas feridas com um caco de 
telha de barro (...) No pequeno círculo pessoal de Jó, com sua esposa e três amigos, a verdade lhe soa mais gloriosa, alegre e verdadeira do que em um simpósio grego ${ }^{5}$ (KIERKEGAARD, SKS 4,56s, grifo nosso).

A trajetória de Jó é um paradigma no seio da antropologia de Kierkgaard. Jó é considerado um paradigma no trajeto de busca pela verdade de si. Essa busca pela verdade é descrita por Kierkegaard por meio da categoria antropológica da repetição (Gentagelse). O livro de Jó retrata, nos termos kierkegaardianos, uma jornada que, a posteriori, mostra-se como uma jornada pela repetição, isto é, uma jornada de tešuvah, de retorno a Deus por meio do retorno a si.

A história de Jó representa uma camada antiga da bíblia hebraica, que remonta ao passado remoto de Israel ${ }^{6}$. Na bíblia hebraica, não há nenhum livro que dedique tanto espaço para um único personagem. Na história de Jó, ocorre uma virada existencial da mesma envergadura da de outros casos paradigmáticos, tais como Moisés (de governador a libertador de escravos) e José (de escravo a governador). No período de Ezequiel, Jó é um paradigma de justiça, junto com Noé e Daniel $(\mathrm{Ez} 14,14)^{7}$. Mas houve uma longa jornada até Jó alcançar a repetição ou retorno a si. Segundo Kierkegaard,

Jó não é herói da fé, ele dá à luz a categoria da provação mediante dores monstruosas (...) A categoria da provação é absolutamente transcendente e posiciona o homem em uma relação-de-contradição com Deus puramente pessoal, uma relação tal que ele não pode dar-se por satisfeito com algum esclarecimento de segunda mão ${ }^{8}$ (KIERKEGAARD, SKS 4,77-78).

\footnotetext{
${ }^{5}$ Det Problem, ved hvilket han er standset, er hverken mere eller mindre end Gjentagelsen. At han ikke sфger Oplysning derom i den graske Philosophi, heller ikke i den nyere, deri gjør han Ret; (...) Gjentagelsen er ogsaa mig for transcendent. Jeg kan omseile mig selv; men jeg kan ikke komme ud over mig selv, dette archimediske Punkt kan jeg ikke opdage. Min Ven søger da heldigviis ikke Oplysning hos nogen verdensberømt Philosoph eller hos nogen professor publicus ordinarius; han tyer til en privatiserende Tanker, (...) Job, der ikke figurerer paa et Katheder og ved betryggende Gesticulationer indestaaer for sine Satningers Sandhed, men som sidder paa Arnestedet og skraber sig med Potteskaar (...) i denne lille Kreds af Job og Kone samt 3 Venner lyder, efter hans Mening, Sandheden herligere og gladeligere og sandere end i et grask Symposium.

6 "O livro de Jó tem uma relação particular com a torah, sobretudo nos círculos saduceus: o livro de Jó é o único, junto com Levítico, do qual se encontrou um targum aramaico em Qumram; é também o único, junto com os da torah, transmitido em escritura hebraica antiga"; "o Talmud babilônico (Baba Batra 14b) o atribui a Moisés, pelo que é considerado um complemento da torah, antes do reconhecimento do caráter canônico da coleção dos profetas" (TREBOLLE BARRERA, 1995, p.193.210).

7 “Jó era [um personagem] proverbial entre os judaítas exilados do séc. VI AEC” (GREENBERG, 1997, p.305).

${ }^{8}$ Job er ikke Troens Helt, han føder »Prøvelsens « Kategori med uhyre Smerter (...) Denne Kategori er absolut transcendent og satter Mennesket $i$ et reent personligt Modsatningsforhold til Gud, i et |4, 78 saadant Forhold, at han ikke kan lade sig nфie med nogen Forklaring paa anden Haand.
} 
Não obstante o reconhecimento do interesse de Deus pelo homem (Jó 7), Jó atravessa esse deserto doloroso de modo amargurado e reivindicatório. Esses dois aspectos marcam a sua reação ao processo de modelagem divina pelo qual ele passa de modo semiconsciente. Amargura (mar) e arguição (rib $\underline{b}$, contenda, disputa) são os dois leitmotivs da reação de Jó. "Em linguagem carregada de termos jurídicos, Jó denuncia a desconsideração de seu direito por Deus” (GREENBERG, 1997, p.312). A metáfora jurídica é nítida, e o próprio Kierkegaard menciona a litigância de Jó no texto de A repetição. Jó é retratado de modo ambíguo, requerendo a audiência, mas ao mesmo tempo reconhecendo a desproporção entre ele e o juiz divino (Jó 9). No capítulo 38, a jornada de Jó apresenta a primeira virada, pelo qual Deus o convoca a sair da posição de arguidor de Deus, instando-a a assumir agora a cadeira de arguido. Após a avassaladora arguição de Deus (Jó 38,1 a Jó 41,26), o ciclo de Jó tem um desfecho (a segunda virada, o retorno a si como caminho de retorno da Deus). Utilizando a expressão cunhada por Kierkegaard em 1848, Jó torna-se "contemporâneo de si mesmo":

Aquele que crê, em comparação com aquele que se auto-tortura, ocupa uma posição diametralmente oposta; porque esse esqueceu completamente o dia de hoje pela preocupação e ocupação com o dia de amanhã. $\mathrm{O}$ crente é um presente [Troende er en Narvaerende], e também um capacitado, como já indica o termo latino prasens. O que se auto-tortura é um ausente e um impotente. No mundo em geral deseja-se com frequência ser contemporâneo com um ou outro grande acontecimento, ou com uma celebridade; acha-se que essa contemporaneidade [Samtidighed] deve ajudar a se desenvolver e tornarse alguém célebre. Talvez! Mas seria mais desejável ser contemporâneo consigo mesmo! Como é raro uma pessoa que é efetivamente contemporânea consigo mesmo; a maioria está há centenas de milhares de quilômetros de si mesmos, imersos nos sentimentos, na imaginação, nos desígnios, resoluções, desejos, ânsias, nas apocalípticas ilusões do espetáculo; ou estão há várias gerações adiante de si mesmos. Mas aquele que crê (o presente) é, no sentido mais elevado, contemporâneo de si mesmo. Este aspecto, a saber, com a ajuda do eterno ser absolutamente contemporâneo consigo mesmo no dia de hoje, é também o que mais forma e desenvolve, essa é a conquista da eternidade. Nunca houve nenhum acontecimento contemporâneo muito menos nenhuma celebridade contemporânea tão grande - como a eternidade. E essa contemporaneidade hoje é justamente a tarefa; quanto a sua resolução, é a fé 9 . (KIERKEGAARD, SKS 10,83, grifo nosso)

\footnotetext{
${ }^{9}$ Den Troende er, sammenlignet med Selvplageren, lige modsat stillet; thi denne glemmer aldeles den Dag Idag af Bekymring for og beskjeftiget med den naste Dag. Den Troende er en Narvarende, og tillige hvad dette Ord $i$ hiint fremmede Sprog betegner en Magtig. Selvplageren er en Fravarende, en Afmagtig. Det Ønske høres ofte $i$ Verden at vare samtidig med een eller anden stor Begivenhed, eller stor Mand; man mener, at Samtidigheden maatte udvikle En og gjфre En til noget Stort. Maaskee! Men skulde det ikke vare noget mere end et Ønske vard at vare samtidig med sig selv! Thi hvor sjeldent et Menneske, der virkelig er samtidig med sig selv; de Fleste ere gjerne i Følelse, i Indbildning, i Forsat, i Beslutning, i Ønske, i Langsel, apokalyptisk, i Skuespils-Skuffelse hundrede tusinde Mile forud for sig selv, eller adskillige Menneske-Aldere forud for sig selv. Men den Troende (den Narvarende) er i høieste Forstand samtidig med sig selv. Og det, ved det Eviges Hjalp at vare ganske samtidig med sig selv idag, det er ogsaa det meest Dannende og Udviklende, det er Evighedens Vinding. Der var 
Nesse belo discurso, Kierkegaard desenvolve uma interpretação do ensino de Jesus sobre a vivência do tempo cujo enfoque se encontra deliberadamente no presente, rejeitando a angústia com o dia posterior: "não se preocupem com o dia de amanhã, pois o amanhã trará os seus cuidados; basta a cada dia a porção do seu mal” (Mt 6,34). Nesse trecho está contida uma das expressões mais memoráveis dos discursos de Kierkegaard, pela sua riqueza do trocadilho - Troende er en Narvarende, “o crente é um presente", presente no sentido temporal e no sentido efetivo de uma presença vigente e vigorante. Embora o jovem cujo perfil psicológicoexistencial retratado na obra $A$ repetição não alcance a resolução da tarefa (a fé), esse jovem se aproximação da contemporaneidade consigo mesmo, contemplando a vida privada de um hebreu, de um personagem icônico da bíblia hebraica:

O jovem felizmente não procura clarificação em algum filósofo mundialmente famoso ou em algum professor publicus ordinarius; ele se volta para um pensador na sua vida particular. (...) No pequeno círculo de Jó, com sua esposa e amigos, a verdade the soa mais gloriosa, alegre e verdadeira do que em um simpósio grego (KIERKEGAARD, SKS 4,56).

Após um período de experiências difíceis, a graça de Deus, implícita do início ao fim, manifesta-se e fornece a Jó a capacidade de repetição como retorno a si, tornando-se contemporâneo de si mesmo como nunca antes até então. Jó torna-se prcesens, ele efetivamente repousou, "sabatizou" o coração, à medida que seu coração conheceu a Deus não por terceiros, mas mediante uma experiência própria.

Jó não é herói da fé, ele dá à luz a categoria da provação mediante fortes dores (...) A categoria da provação é absolutamente transcendente e posiciona o homem em uma relação-de-contradição com Deus puramente pessoal, uma relação tal que ele não pode dar-se por satisfeito com algum esclarecimento de segunda mão ${ }^{10}$ (KIERKEGAARD, SKS 4,77-78).

da vel heller aldrig nogen samtidig Begivenhed, ei heller nogen høistaret Samtidig saa stor - som Evigheden. Og denne Samtidighed idag er just Opgaven; naar den lфses, er det Troen.

10 Job er ikke Troens Helt, han føder »Prфvelsens «Kategori med uhyre Smerter (...) Denne Kategori er absolut transcendent og satter Mennesket i et reent personligt Modsatningsforhold til Gud, i et |4, 78 saadant Forhold, at han ikke kan lade sig nøie med nogen Forklaring paa anden Haand. 


\section{Considerações finais}

Nos estudos Kierkegaard é comum pensar a relação do pensador dinamarquês com a tradição judaica mediante a figura de Abraão, trabalhada por ele na obra Temor e Tremor, de 1843. No entanto, como mostramos, a figura de Jó é fundamental para pensarmos a noção hebraica de tempo na antropologia de Kierkegaard. Neste artigo discutimos dois modos de vivenciar o tempo: uma experiência desesperada do tempo - o tempo como agente corrosivo, e uma experiência sagrada do tempo - o tempo como receptáculo da redenção. A fornalha devoradora, nos termos de Kierkegaard, é uma experiência do tempo na qual não há instante efetivo. A noção hebraica de tempo que emerge do relato cosmogônico de Genesis 2 (a tríade redentora do sétimo dia) faz-se presente na obra de Kierkegaard desde o insight de 1837, logo no começo de sua obra, e se manifesta em diversos momentos, notadamente em 1843 (o caso de Jó em A repetição), em 1844 (a noção de instante em Conceito de Angústia) e em 1848 (a noção de contemporaneidade consigo mesmo em Discursos do evangelho). Estas três categorias existenciais de Kierkegaard refletem, à sua maneira, a tríade cosmogônica redentora de Genesis: $\check{s} b t$, brk e $q d \check{s}$ - repousar, abençoar e santificar. Com a discussão desse aspecto, objetivamos salientar um dos fios da relação entre a antropologia da existência e o mistério da criação, no seio do qual emerge a tarefa da experiência do tempo. Que este fio contribua para que outros fios da antropologia da redenção do homem e do tempo sejam desenovelados.

\section{Bibliografia}

BÍBLIA. Trad. Nova Almeida Atualizada. São Paulo: SBB, 2017.

GREENBERG, M. "Jó" in ALTER, R. KERMODE, F. Guia literário da bíblia. Trad. R. Fiker. São Paulo: Edunesp, 1997.

KIERKEGAARD, S. Søren Kierkegaards Skrifter (SKS). Editados pelo S. K. Forskningscenteret. Copenhague, 2014. Versão eletrônica disponível em <www.sks.dk>. Acesso em 30 nov. 2021.

HESCHEL, A. O shabat - o seu significado para o homem moderno. Trad. F. Kon e J. Guinsburg. São Paulo: Perspectiva, 2014.

TREBOLLE-BARRERA, J. A bíblia judaica e a bíblia cristã. Trad. R. Mincato. Petropolis: Vozes, 1995.

WOLFF, H. Antropologia do antigo testamento. Trad. Antonio Steffen. São Paulo: Loyola, 1975. 